\title{
Severe Hypocalcemia in a Patient with Recurrent Chondrosarcoma
}

\author{
Jung Nam Eun ${ }^{1}$, Yoo Duk Choi ${ }^{2}$, Jeong Ho Lee ${ }^{1}$, Yun Ah Jeong ${ }^{1}$, \\ Jee Hee Yoon ${ }^{1}$, Hee Kyung Kim ${ }^{1}$ and Ho-Cheol Kang ${ }^{1}$
}

\begin{abstract}
Hypocalcemia is relatively uncommon paraneoplastic syndrome. Only one case of hypocalcemia has been reported in a patient with chondrosarcoma. We herein report a case of a 32-year-old woman with metastatic chondrosarcoma with tetany. Her imaging findings revealed multiple calcific metastatic lesions in the lungs, pancreas, left atrium, and pulmonary vein. A laboratory examination showed hypocalcemia with no evidence of any other disease that could induce hypocalcemia. On the basis of the laboratory and clinical findings, we concluded the etiology of her severe hypocalcemia to be excessive calcium consumption by the tumor itself.
\end{abstract}

Key words: hypocalcemia, chondrosarcoma, osteoblastic metastases

(Intern Med 56: 1839-1842, 2017)

(DOI: 10.2169/internalmedicine.56.7884)

\section{Introduction}

Hypercalcemia is a well-known paraneoplastic syndrome relating to both solid tumors and hematologic malignancies and is considered a poor prognostic factor (1). Clinically, severe hypocalcemia and hyperphosphatemia are relatively uncommon paraneoplastic syndromes. Prostate or breast cancer may lead to hypocalcemia via osteoblastic metastasis, whereby calcium deposits occur in newly formed bone around the tumor (2). Patients with medullary thyroid carcinoma may present with hypocalcemia due to tumoral secretion of calcitonin (3); however, chondrosarcoma rarely manifests with hypocalcemia, and, to our knowledge, only one case of hypocalcemia has been reported in a patient with chondrosarcoma (4). We herein report a case of a multiple calcific metastatic chondrosarcoma with hypocalcemia, whereby the mechanism of hypocalcemia was excessive consumption of calcium by the tumor.

\section{Case Report}

A 32-year-old woman presented with tetany. She had undergone surgery for mesenchymal chondrosarcoma of the left femur five years earlier, with a recurred lesion three years thereafter (Fig. 1). However, multiple calcific metastases were detected in the lungs and pancreas during a routine follow-up examination, and systemic chemotherapy was planned. She had no history of malnutrition or of gastrointestinal or renal disease. Her vital signs were as follows: blood pressure, $100 / 70 \mathrm{mmHg}$; pulse rate, 76 beats/min; respiratory rate, 20 breaths $/ \mathrm{min}$; and body temperature, $36.2^{\circ} \mathrm{C}$. A physical examination revealed positive results for Trousseau's and Chvostek's signs. A laboratory examination revealed hypocalcemia; her albumin-modified serum total calcium level was $5.2 \mathrm{mg} / \mathrm{dL}$ (normal range: $8.4-10.2 \mathrm{mg} / \mathrm{dL}$ ), her ionized calcium level was $1.34 \mathrm{mEq} / \mathrm{L}$ (normal range: 2.2-2.6 mEq/L), and her serum phosphate level was $7.3 \mathrm{mg} /$ $\mathrm{dL}$ (normal range: $2.5-5.53 \mathrm{mg} / \mathrm{dL}$ ). There was no evidence of hypoalbuminemia $(4.0 \mathrm{~g} / \mathrm{dL})$, hypomagnesemia $(2.3 \mathrm{mg} /$ dL), renal failure [blood urea nitrogen (BUN)/Cr $9.0 / 0.7 \mathrm{mg} /$ $\mathrm{dL}$, estimated glomerular filtration rate (eGFR) $96.97 \mathrm{~mL} /$ $\mathrm{min} / 1.73 \mathrm{~m}^{2}$ ], or malabsorption. Additional laboratory evaluations for hypocalcemia revealed hypocalciuria (24-h urine calcium level: $8 \mathrm{mg} /$ day) and hypophosphaturia (24-h urine inorganic phosphorus level: $0.25 \mathrm{~g} /$ day) following calcium infusion, as well as a low serum level of 25 -hydroxyvitamin D $(14.5 \mathrm{ng} / \mathrm{mL})$ and a high level of parathyroid hormone

\footnotetext{
${ }^{1}$ Department of Internal Medicine, Chonnam National University Hwasun Hospital, Chonnam National University Medical School, Korea and ${ }^{2}$ Department of Pathology, Chonnam National University Hwasun Hospital, Chonnam National University Medical School, Korea Received for publication June 22, 2016; Accepted for publication August 29, 2016
} Correspondence to Dr. Hee Kyung Kim, albeppy@jnu.ac.kr 

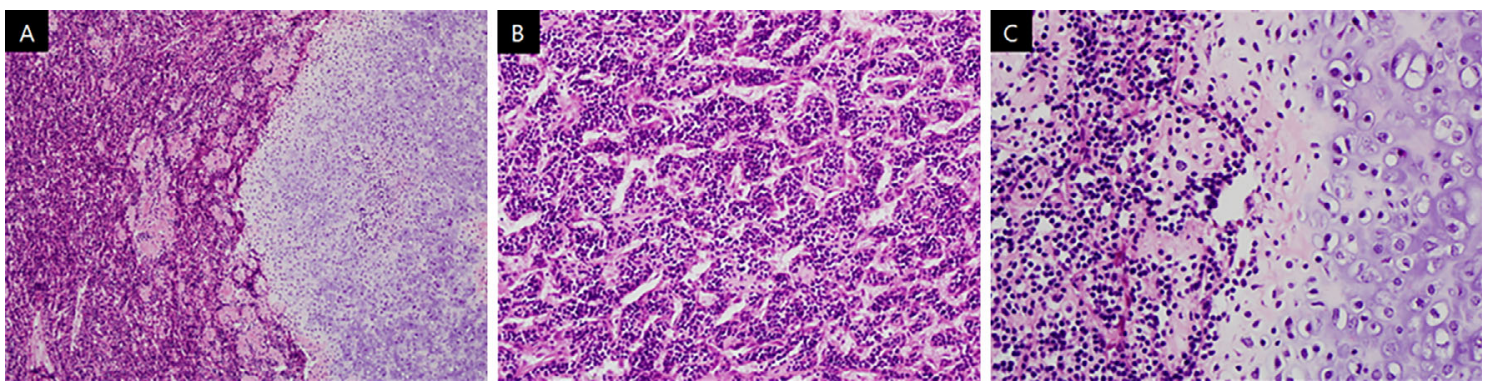

Figure 1. A biopsy of the recurred lesion showed features of mesenchymal chondrosarcoma. (A) Mesenchymal chondrosarcoma with chondroid areas (right), Hematoxylin and Eosin (H\&E) staining, original magnification 100x. (B) Mesenchymal chondrosarcoma with undifferentiated small round cells, H\&E staining, original magnification 200×. (C) Undifferentiated small round cells and cartilage differentiation, H\&E staining, original magnification 1,000×.

Table. General Laboratory Data at the Time of Diagnosis.

\begin{tabular}{lcc}
\hline \multicolumn{1}{c}{ Title } & Reference range & $\begin{array}{c}\text { Patient's } \\
\text { value }\end{array}$ \\
\hline WBC $\left(/ \mathrm{mm}^{3}\right)$ & $4,000-10,800$ & 5,700 \\
Absolute neutrophil count $\left(/ \mathrm{mm}^{3}\right)$ & $3,800-7,500$ & 3,070 \\
Hemoglobin $(\mathrm{g} / \mathrm{dL})$ & $12-18$ & 13.5 \\
Platelet $\left(10^{3} / \mathrm{mm}^{3}\right)$ & $130-450$ & 307 \\
Total protein $(\mathrm{g} / \mathrm{dL})$ & $5.8-8.1$ & 6.7 \\
Albumin $(\mathrm{g} / \mathrm{dL})$ & $3.1-5.2$ & 4.0 \\
AST $(\mathrm{U} / \mathrm{L})$ & $7-38$ & 36 \\
ALT $(\mathrm{U} / \mathrm{L})$ & $6-42$ & 13 \\
Total bilirubin $(\mathrm{mg} / \mathrm{dL})$ & $0.35-1.3$ & 0.5 \\
BUN $(\mathrm{mg} / \mathrm{dL})$ & $8-23$ & 9.0 \\
Creatinine $(\mathrm{mg} / \mathrm{dL})$ & $0.5-1.3$ & 0.66 \\
CRP $(\mathrm{mg} / \mathrm{dL})$ & $0-0.3$ & 2.78 \\
\hline
\end{tabular}

(PTH; 147.50 pg/mL; normal range: $15-68.3 \mathrm{pg} / \mathrm{mL}$ ). Bone turnover markers were within normal limits; the level of osteocalcin was $15.63 \mathrm{ng} / \mathrm{mL}$ (normal range: $11-48 \mathrm{ng} / \mathrm{mL}$ ), and serum C-terminal telopeptide (CTX) was $0.338 \mathrm{ng} / \mathrm{mL}$ (normal range: $0.01-1 \mathrm{ng} / \mathrm{mL}$ ), both of which were measured using an electrochemiluminescence immunoassay (Cobas e601, Roche Diagnostics GmbH, Mannheim, Germany). The levels of serum fibroblast growth factor 23 (FGF-23) and 1,25-dihydroxyvitamin D were not checked. Other laboratory data, such as a complete blood count and the liver and renal function, are presented in Table. Chest X-ray imaging revealed multiple spherical lesions in both lungs (Fig. 2), and computed tomography revealed multiple calcific metastatic lesions in the lungs, pancreas, left atrium, and pulmonary vein (Fig. 3).

High doses of calcium and an active vitamin D replacement for severe hypocalcemia were initiated, and three cycles of chemotherapy with adriamycin and ifosfamide were administered. Follow-up laboratory analyses revealed elevated total and ionized calcium levels, which correlated with the chemotherapy, rather than calcium replacement (Fig. 4). Her symptoms and abnormal findings on the initial physical examination (i.e. Trousseau's and Chvostek's signs) were

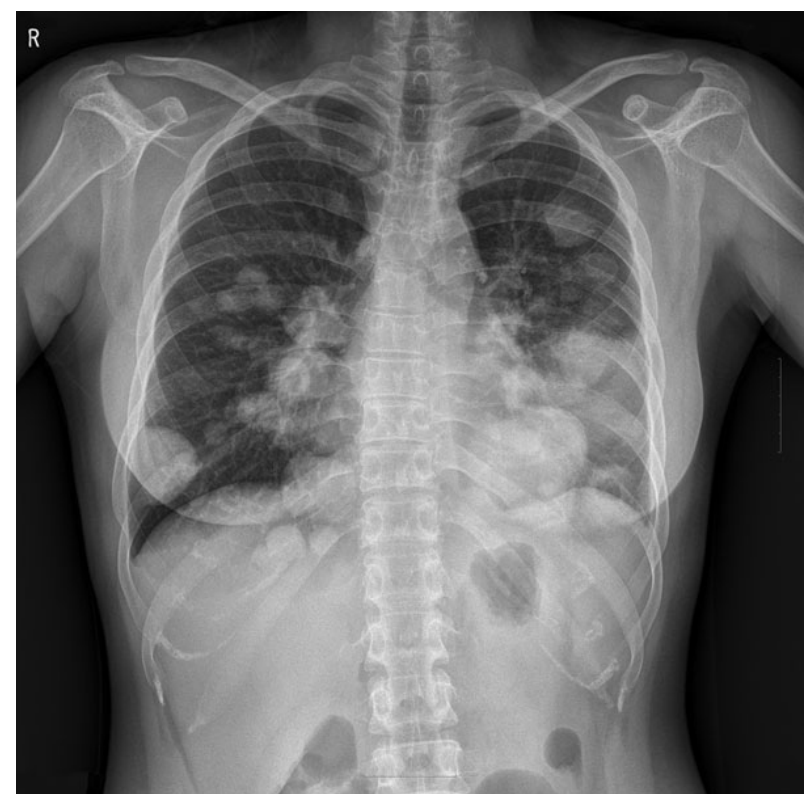

Figure 2. Chest X-ray image showing multiple spherical lesions in both lungs.

improved. Unfortunately, however, hemoptysis occurred, leading to respiratory failure despite chemotherapy and supportive care, and the patient died three months after the recurrence.

\section{Discussion}

Hypercalcemia is a common paraneoplastic syndrome that is mediated by several mechanisms, including humoral hypercalcemia of the malignancy, which is mediated by PTHrelated protein (PTHrP); it is associated with squamous cell lung cancers, as well as local osteolytic invasion in multiple myeloma, active vitamin D secretion by tumor cells in lymphoma, and PTH secretion in primary parathyroid carcinoma (5). In contrast, hypocalcemia rarely occurs as a direct result of the tumor itself; rather, it occurs as a treatmentinduced complication during the correction of cancerassociated hypercalcemia (i.e. during the administration of 

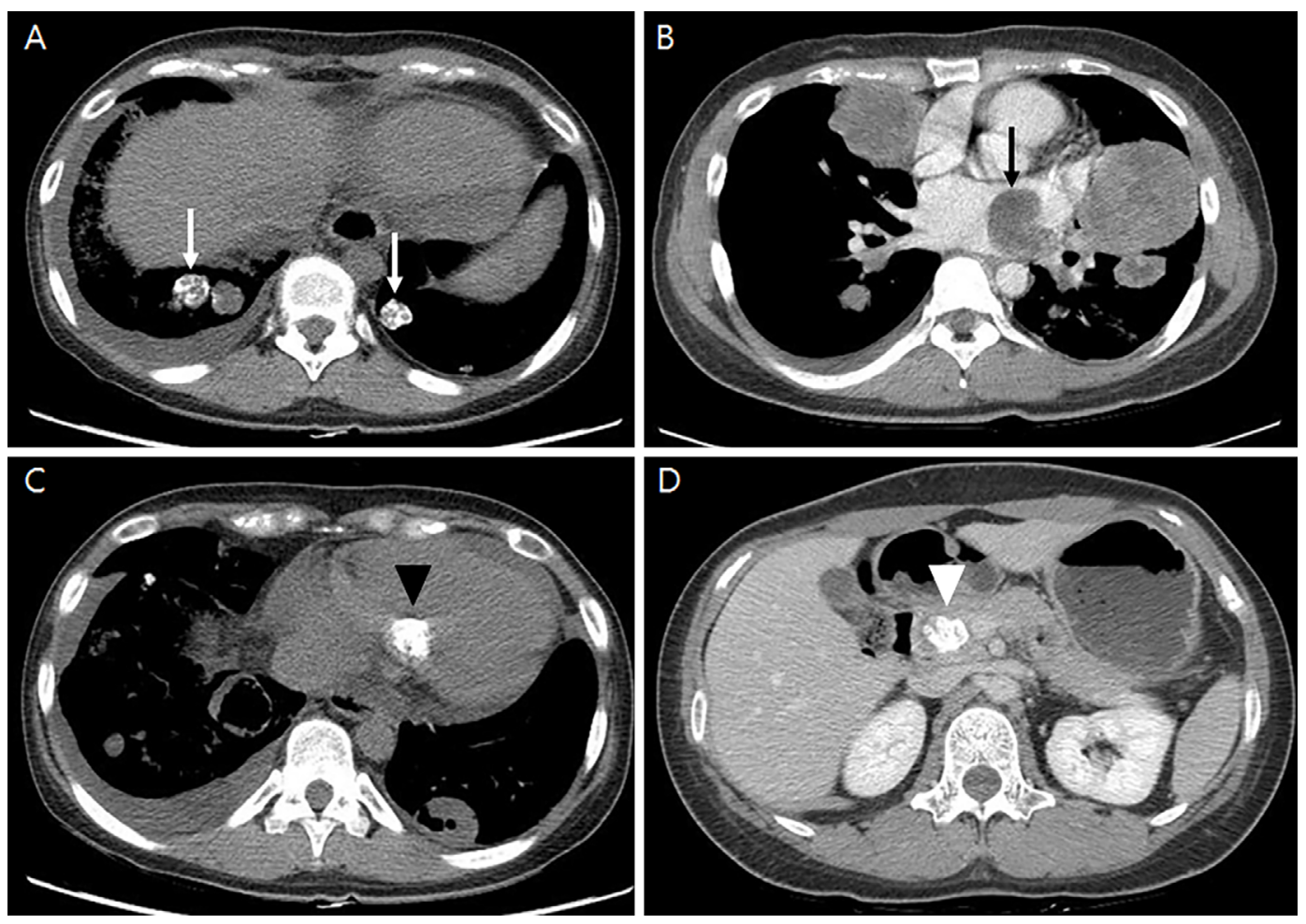

Figure 3. Computed tomography scan showing multiple calcified metastatic lesions in the lung (A: white arrows), left atrium (B: black arrow), left pulmonary vein (C: black arrow head), and pancreas (D: white arrow head).

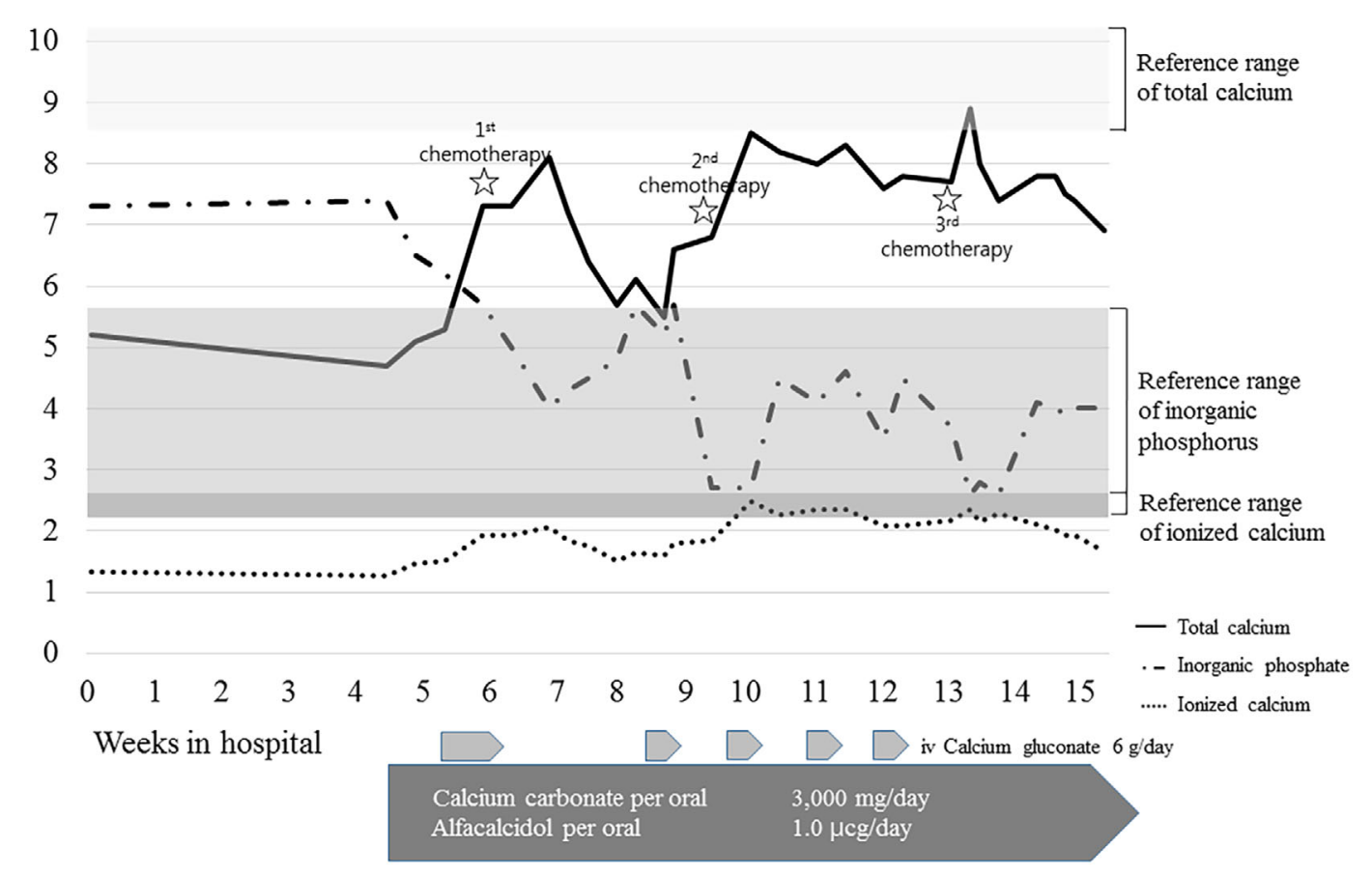

Figure 4. Serial follow-up measurements of the patient's calcium and inorganic phosphate levels.

bisphosphonate or denosumab) $(6,7)$, or during hypoparathyroidism following thyroid, head, or neck surgery (8). Occasionally, aggressive osteoblastic metastases (e.g. prostate or breast cancer) may induce hypocalcemia due to the rapid mineralization of newly formed bone $(4,5)$; however, hy- pocalcemic episodes are rare in patients with chondrosarcoma.

Chondrosarcomas are malignant bone tumors that produce a chondroid matrix. Conventional chondrosarcomas are lowto intermediate-grade tumors that grow slowly and have low 
metastatic potential. However, high-grade chondrosarcomas, including some conventional chondrosarcomas and rare variants, have high metastatic potential and a poor prognosis (9). Mesenchymal chondrosarcoma is one of the rarer and more highly malignant subtypes of chondrosarcoma; it occurs more frequently in extra-skeletal primary tumors than other subtypes (10).

Chondrosarcoma results in various symptoms depending on the subtype and involved organ. Although it has been reported that chondrosarcoma show calcification in extraskeletal and metastatic lesions (11-13), it rarely leads to severe hypocalcemia. Our patient exhibited normal calcium and phosphate levels during remission following surgery, and hypocalcemia was evident only following the diagnosis of recurrence. Therefore, severe hypocalcemia may result from extensive tumoral consumption of calcium by osteoblastic metastases of the chondrosarcoma. Other causes of hypocalcemia with high PTH levels were excluded (e.g. vitamin D deficiency, chronic kidney disease, and PTH resistance). Furthermore, the temporal variation in our patient's calcium levels correlated with the chemotherapy. It has been reported that elevated phosphate levels are associated with osteoblast-induced hypocalcemia (14) in combination with hypoparathyroidism. In our case, the elevated phosphate levels occurred in combination with increased PTH levels; however, these recovered to normal limits within 2 weeks, despite the continued hypocalcemia, which may have been caused by an insufficient immediate PTH response. If her levels of serum FGF-23 and active vitamin D had been assessed, these data would have helped us differentiate the pathophysiology of her hyperphosphatemia; however, they were not checked. Low levels of urinary calcium excretion were found following calcium infusion, consistent with previous observations $(4,7)$. This suggests that the calcium consumption associated with the malignancy occurred indirectly.

In conclusion, we described a rare case of severe hypocalcemia associated with chondrosarcoma. The hypocalcemia appears to have been caused by excessive calcium consumption by the tumor itself, which is relatively common in patients with osteoblastic tumors. Regular follow-up measurements of serum calcium levels are necessary in patients with malignant diseases-not just to screen for hypercalcemia, but also to identify hypocalcemia.

The authors state that they have no Conflict of Interest (COI).

\section{References}

1. Stewart AF. Hypercalcemia associated with cancer. N Engl J Med 352: 373-379, 2005.

2. Smallridge RC, Wray HL, Schaaf M. Hypocalcemia with osteoblastic metastases in patient with prostate carcinoma. A cause of secondary hyperparathyroidism. Am J Med 71: 184-188, 1981.

3. Tashjian AHJ, Melvin KEW. Medullary carcinoma of the thyroid gland. N Engl J Med 279: 279-283, 1968.

4. Relkin R. Hypocalcemia resulting from calcium accretion by a chondrosarcoma. Cancer 34: 1834-1837, 1974.

5. Fallah-Rad N, Morton AR. Managing hypercalcaemia and hypocalcaemia in cancer patients. Curr Opin Support Palliat Care 7: 265-271, 2013

6. Qi WX, Lin F, He AN, Tang LN, Shen Z, Yao Y. Incidence and risk of denosumab-related hypocalcemia in cancer patients: a systematic review and pooled analysis of randomized controlled studies. Curr Med Res Opin 29: 1067-1073, 2013.

7. Maalouf NM, Heller HJ, Odvina CV, Kim PJ, Sakhaee K. Bisphosphonate-induced hypocalcemia: report of 3 cases and review of literature. Endocr Pract 12: 48-53, 2006.

8. Demeester-Mirkine NN, Hooghe LL, Van Geertruyden JJ, De Maertelaer VV. Hypocalcemia after thyroidectomy. Arch Surg 127: 854-858, 1992.

9. Angelini A, Guerra G, Mavrogenis AF, Pala E, Picci P, Ruggieri P. Clinical outcome of central conventional chondrosarcoma. J Surg Oncol 106: 929-937, 2012.

10. Rushing EJ, Armonda RA, Ansari Q, Mena H. Mesenchymal chondrosarcoma: a clinicopathologic and flow cytometric study of 13 cases presenting in the central nervous system. Cancer 77: 1884-1891, 1996.

11. Khan FQ, Mari AR, Afzal R. Sphenoidal intracranial chondrosarcoma. J Coll Physicians Surg Pak 24 (Suppl 1): S34-S36, 2014.

12. Khouja N, Ben Amor S, Jemel H, Kchir N, Boussen H, Khaldi M. Mesenchymal extraskeletal chondrosarcoma of the orbit. Report of a case and review of the literature. Surg Neurol 52: 50-53, 1999.

13. Maile CW, Rodan BA, Godwin JD, Chen JT, Ravin CE. Calcification in pulmonary metastases. Br J Radiol 55: 108-113, 1982.

14. Sackner MA, Spivack AP, Balian LJ. Hypocalcemia in the presence of osteoblastic metastases. N Engl J Med 262: 173-176, 1960 .

The Internal Medicine is an Open Access article distributed under the Creative Commons Attribution-NonCommercial-NoDerivatives 4.0 International License. To view the details of this license, please visit (https://creativecommons.org/licenses/ by-nc-nd/4.0/).

(C) 2017 The Japanese Society of Internal Medicine http://www.naika.or.jp/imonline/index.html 